\title{
La pluralidad lingüística en la novela helenizante posterior al Persiles*
}

\author{
José Luis Losada PalenZuela**
}

\begin{abstract}
Resumen
La presencia o mención de lenguas extranjeras en una obra literaria es un recurso ficcional que se remonta a la literatura clásica griega. Cervantes lo introduce en su novela póstuma Persiles (1617), inspirándose en Las etiópicas de Heliodoro. Este artículo se centra en dos novelas helenizantes posteriores, Semprilis y Genorodano (1629) y Eustorgio y Clorilene (1629) para interrogarlas críticamente sobre la pluralidad de lenguas y la supuesta dependencia de sus modelos literarios. Hemos optado por el enfoque narratológico definido como glotoliteratura, que nos permite modelar los diálogos entre personajes dependiendo de cómo las referencias a una lengua extranjera interactúan entre los niveles de la historia y el discurso. Concluiremos considerando que estas novelas son principalmente glotodiegéticas y usan esta instancia para reforzar la verosimilitud, relacionándolo de forma directa a la tradición de los manuales de educación de príncipes.
\end{abstract}

Palabras clave: Glotoliteratura; multilingüismo; manual de educación de príncipes; Persiles; Semprilis; Eustorgio.

\section{Title: Multilingualism in the Spanish Byzantine Novel after Persiles}

\begin{abstract}
The presence or mention of foreign languages in a literary work is a common fictional device which can be traced since ancient Greek literature. Cervantes introduces it in his posthumous novel Persiles taking inspiration from the Aethiopica of Heliodorus. This paper focus on two later Spanish Byzantine novels Semprilis y Genorodano (1629), Eustorgio $y$ Clorilene (1629) in order to critically interrogate them about their multilingualism

* Este trabajo ha sido en parte posible gracias a la estancia de investigación en la Universidad de Ginebra en el marco del proyecto "Beyond the canon: the Byzantine genre in the Spanish baroque literature" financiado por el Fonds national suisse de la recherche scientifique (FNS, Nr. IZSEZ0_183687).

** Universidad de Wrocław. jose-luis.losada@uwr.edu.pl / ORCID iD: https://orcid.org/00000002-6530-1328.
\end{abstract}


and their alleged distance to the literary models. We have adopted the narratological approach defined as glotta-literature, which allows us to model the dialog between characters depending on how references to a foreign language interact at the levels of histoire and discourse. We will conclude by suggesting that these novels are mainly glotta-diegetic and use this instance to reinforce the principle of verisimilitude, closely tied to the tradition of mirrors for princes literature.

Keywords: Glotta-literature; Multilingualism; Mirrors for Princes Literature; Persiles; Semprilis; Eustorgio.

\section{Cómo citar este artículo / Citation}

Losada Palenzuela, José Luis. 2020. «La pluralidad lingüística en la novela helenizante posterior al Persiles». Anales Cervantinos 52: 283-300, https://doi.org/10.3989/anacervanti nos.2020.011.

\section{INTRODUCCIÓN}

La España del Siglo de Oro es consciente, en la esfera política, social y estética, de la pluralidad lingüística. Un buen ejemplo institucional nos lo ofrece la Secretaría de Interpretación de Lenguas fundada en 1527 por Carlos V como órgano auxiliar del Consejo de Estado para abordar la traducción de correspondencia que generaba la intensa labor de gobierno. El emperador colocó al frente de la oficina a Diego Gracián, cargo que permanecería durante casi doscientos años en la influyente familia de los Gracianes, traductores, escritores y censores muy próximos a la corte y a la vida intelectual del Siglo de Oro (Cáceres 2004, 610-611). Numerosos son los testimonios socioculturales del aumento de la conciencia lingüística gracias a contactos intra e interculturales (Martinell 2000) durante la conquista y la exploración americanas o en las zonas de contacto europeas como Italia, Francia, Alemania o Países Bajos. Gramáticas, vocabularios y tesauros empiezan a tener una gran difusión (Sánchez Pérez 1992, 7-142) y se reconoce paulatinamente la importancia del aprendizaje de lenguas, no solo para la educación de la nobleza o para el entorno diplomático (Martínez y Martinell 2017), sino también para mercaderes, cortesanos o viajeros, como ya se nos indica en el prólogo al lector de un diccionario de diálogos en cuatro lenguas:

... que alguno entienda en mercadería o que ande en corte o que siga la guerra o camina por tierras estrañas [...] no tenéis necesidad de faraute [intérprete], ma las podréis de vos mismo hablar [...] ¿Quién pudo jamás con una lengua alcançar la amistad de diversas nationes? ¿Cuántos pudieron enriquecer sin noticia de muchas lenguas?¿Quién supo bien gobernar ciudades y provincias, $\sin$ saber otra lengua que la suya maternal? (Berlaimont $1608,2 \mathrm{v} .^{\circ}-3 r^{\circ}$ ). 
Resulta, por tanto, coherente que la pluralidad lingüística encuentre un reflejo en la literatura. En la narrativa áurea se despliegan los motivos relacionados con el papel del traductor y del intérprete, con la incomunicación o dificultad de comprenderse, con el aprendizaje lingüístico, con las lenguas para el buen gobierno, etc., que constatan la importancia de la «cognición de lenguas», como escribe Baltasar Gracián en El Discreto, donde las considera además «llaves del mundo» (Gracián 1997, 359).

La internacionalización del espacio ficcional en la novela bizantina -uso por convención el término bizantino, aunque debería hablarse con propiedad de género helenizante- ${ }^{1}$ impulsa la exigencia de tematizar el uso de lenguas, constituyendo un rasgo característico del género, aunque no faltan en el teatro del Siglo de Oro (Canonica 1991, 1996, 2002) ni en la picaresca ni en el Quijote; tampoco, desde luego, en el Persiles como han estudiado, entre otros, Canonica (1994) o Egido (2007), quienes han destacado que la emulación cervantina recoge el llamado poliglotismo implícito presente ya en Las etiópicas de Heliodoro.

En este trabajo quisiera ampliar el foco de la pluralidad lingüística como marca de género a dos novelas consideradas imitaciones epigonales del Persiles, que han sido poco estudiadas por la crítica: Semprilis y Genorodano (1629) y, en particular, Eustorgio y Clorilene (1629). No les falta casi ninguna de las características típicas del género: pareja de enamorados, comienzo in medias res, analepsis, tramas paralelas, matrimonios múltiples, piratas, travesías marítimas, ni tampoco una configuración narrativa donde la pluralidad lingüística alcanza mucha relevancia.

Describiré el fenómeno sirviéndome del concepto de glotoliteratura (Stockhammer 2015) para clasificar metodológicamente la interacción de personajes y lenguas, que posteriormente analizaré en relación con su importancia en la instrucción del protagonista. Concluiré mostrando que las novelas son principalmente glotodiegéticas, se sirven del recurso para sustentar con verosimilitud el relato y para reforzar, sobre todo Suárez de Mendoza, la novelización de la educación de príncipes.

\section{EL CONCEPTO DE PLURALIDAD LINGÜÍSTICA EN LITERATURA}

La presencia de lenguas extranjeras de forma explícita o implícita en una obra literaria, el uso de una lengua distinta a la que ofrece el texto base (Ca-

1. Variante propuesta por Torres $(2009,572)$ y Blanco $(2016,124)$ para superar la indeterminación del término bizantino. Entiendo por género helenizante las novelas publicadas en España durante el XVI y XVII que toman como referencia los modelos clásicos de la novela griega, sobre todo de Heliodoro o de Aquiles Tacio. El problema terminológico no desaparece en inglés. Armstrong-Roche (2009) evita usar 'Byzantine', sirviéndose de 'adventure novel' y, en particular, 'epic novel', término central de su magnífico trabajo. A falta de un término adecuado en inglés (y espacio para la discusión) para este género narrativo del Siglo de Oro prefiero mantener en el título en inglés y en el resumen "Spanish Byzantine novel". 
nonica 1996, 109), es un recurso común de muchas literaturas. Podemos definir este tipo de textos como un espacio literario en el que se cruzan varias lenguas o registros, préstamos léxicos, diálogos en lenguas imaginarias, citas de autores extranjeros, recursos metalingüísticos o fonéticos, menciones directas, indirectas o veladas (Grutman 2002). Constituye desde los clásicos un hecho evidente, aunque su análisis y su descripción no se ha desarrollado sin valoraciones o interpretaciones divergentes, como apuntan Brugnolo y Orioles $(2002,10)$ en el volumen monográfico Eteroglossia e plurilinguismo letterario $^{2}$. Multi-, pluri- o bilingüismo suelen ser usados indistintamente como la habilidad de sociedades o individuos de servirse de más de una lengua; en un sentido similar se usa poliglotismo, aunque está siendo relegado en el ámbito de la Lingüística y disciplinas afines por multilingüismo. Los estudios literarios vienen adaptándolos a sus fines, piénsese, por ejemplo, en el concepto de code-switching -la mezcla de varias lenguas en un enunciado (Winford 2003)-, aunque también han acuñado propios, como el caso del concepto de heteroglosia de Bajtín ${ }^{3}$.

Simplificando, las perspectivas adoptadas varían dependiendo de si el foco se pone en el creador o en el texto. La balanza tiende a inclinarse hacia trabajos que buscan razones socioliterarias, manifestaciones de una realidad social plurilingüe, de testimonios de lenguas en contacto o de poetas poliglotas, más que hacia el análisis de una técnica poética explícita limitada al plano discursivo, la cual queremos abordar en este trabajo.

En la literatura del Siglo de Oro fueron pioneros los estudios de Canonica dedicados al teatro de Lope de Vega y a la obra de Cervantes, para los que propuso el concepto de poliglotismo. El término parte del trabajo de Forster $(1970,2)$ sobre escritores políglotas y sus obras (no necesariamente políglotas). Muchos de estos escritores "produce not only poems in different languages, but also polyglot poems, or poems made of "international" words» (Forster 1970, 89), es decir, alternando varias lenguas, dando por sentado que se trata de lenguas explícitamente mencionadas.

Canonica retoma el concepto de poliglotismo (la introducción de palabras y frases enteras en otra lengua natural) para demostrar que «en lo que atañe al teatro español, el poliglotismo es el resultado de un plurilingüismo previo» $(1996,109)$. En un principio basa su concepto de plurilingüismo en la perspectiva del autor, es decir, en las lenguas que domina, habla o en las que está en contacto sin apartarse de la justificación del referente real. Sin embargo, propone también el término de poliglotismo implícito:

2. Amplísima es ya la variedad terminológica que recorre sus diversos artículos. Sufijos construidos sobre el latino lingua (lengua) tenemos pluri-, multi-, trans-, inter-, bi-, hetero-, misti-: plurilingüismo, multilingüismo, translingüismo, interlingüismo, bilingüismo, hétérolinguisme (fr), mistilinguismo (it); sufijos construidos sobre el griego $\gamma \lambda \tilde{\omega} \sigma \sigma \alpha$ ( $g l \bar{s} s s a$, lengua) o $\gamma \lambda \tilde{\omega} \tau \tau \alpha$ (glōtta, lengua): hetero-, poli-, di-, allo-: heteroglosia, poliglotismo, diglosia, alloglossia (it).

3. En propiedad, el término (hétéroglossie) se debe a la traducción de Todorov del orignal ruso (raznorechie). Todorov elige hétéro- para destacar más la diferencia que la pluralidad (1981, 42). La traducción española se decanta por plurilingüismo (Bajtín 1989, 77-236). 
Lo que llama la atención no es tanto el poliglotismo explícito sino el implícito, que se manifiesta en una serie de justificaciones de tipo metalingüístico acerca de la lengua efectivamente hablada por tal personaje extranjero, al que Cervantes hace hablar en español (Canonica 1991, 22-23).

En el análisis de Cervantes la idea se retomará en Brioso (2002), Pelorson (2003), Egido (2007) y Canavaggio (2014) para resaltar los problemas de comunicación lingüística como parte de la fábula del Persiles, donde se tematizan a menudo los gestos, la mediación del intérprete o traductor, el aprendizaje autónomo o dirigido, la incomunicación, etc ${ }^{4}$. Aunque Cervantes ya prefigura muchos de estos aspectos en La Galatea, La española inglesa o el Quijote (piénsese en los personajes de Zoraida o Cide Hamete), pues la «variedad idiomática en el Quijote es inseparable de la variedad geográfica, racial, cultural y religiosa» (Egido 2007, 38), el Persiles multiplicará estos aspectos en sus páginas, representando todo un «polyglot world» (Armas 2000, 104).

Sin duda, el poliglotismo implícito es una marca de nuestras novelas, que siguen la tradición de la influencia griega y cervantina. Para su análisis, sin embargo, quisiera atreverme a usar otra terminología que toma como perspectiva exclusivamente el texto literario. Cierto es que la experiencia vital de Cervantes puede explicar, por ejemplo, el uso de términos turcos en sus obras, pero también deberían explicarse como elección estética las menciones al polaco, moscovita, tártaro, etc., que recorren muchas páginas del género, para marcar el exotismo, la verosimilitud de los personajes, la incomunicación, etc.

Debido al predominio de trabajos que abordan el contexto del autor donde surge una obra multilingüe, los análisis inmanentes han quedado un poco apartados. Fuera del ámbito hispano encontramos, sin embargo, varios intentos de sistematizar con una taxonomía más precisa todas estas manifestaciones de pluralidad lingüística a nivel discursivo.

\section{NARRACIONES GLOTODIEGÉTICAS}

Algunas de las taxonomías existentes ${ }^{5}$ se centran sobre todo en las formas de representación de la lengua extranjera en la lengua base del texto, en su mayoría explícitas (showing-modus) dentro de los corpus que analizan. Helmich $(2016,17)$, por ejemplo, no toma en consideración las marcas de tra-

4. Trabajos recientes vuelven de nuevo al poliglotismo en el Persiles para relacionarlo con el concepto de lengua perfecta (Sánchez 2019) o para justificar con el concepto de oralidad su cierta incoherencia de uso (Davenport 2016).

5. Destaca la clasificación de Grutman (2002), ejemplificada, entre otros, con el uso del francés en Guerra y Paz de Tolstoi, y la de Radaelli (2014), sobre un corpus alemán. Helmich (2016) ofrece, en sus más de seiscientas páginas, un detallado análisis de obras de la segunda mitad del siglo XX que presentan lenguas extranjeras (con un énfasis especial en literaturas románicas). Recoge un amplio repaso al estado de la cuestión (Helmich 2016, 30-40). 
ducción, paráfrasis o formulación a modo de inquit (es decir, un enunciado del tipo «contestó en toscano», pero sin respuesta en toscano), que aparecen, por el contrario, con mayor frecuencia en nuestras novelas. Este motivo, así como el claro anclaje en la tradición teórica de la narratología y una mayor coherencia terminológica, me lleva a decantarme por otra taxonomía -el concepto de glotoliteratura-, aunque las otras propuestas no sean excluyentes y sus diferencias podrían reducirse a una cuestión terminológica.

La literatura que tematiza el uso de una lengua extranjera podemos denominarla en alemán Glottaliteratur (Stockhammer 2015, 146-172) 6 . El concepto se desarrolla dentro del marco de las distinciones narratológicas clásicas de historia y discurso (histoire, discours) y propone una clasificación según cómo interactúen los significantes literarios de las lenguas entre estos dos niveles. De esta manera, si se reproduce la otredad lingüística hablamos de glotomímesis, pues las lenguas se presentan explícitamente en el discurso (en general correspondería al poliglotismo explícito propuesto con Canonica). Esta se subdivide a su vez en glotomímesis icónica, si entre el discurso y la historia existe plena concordancia, y glotomímesis indicativa, si solo presenta indicios parciales de las lenguas en el discurso. Si en vez de reproducir, solo se marca la otredad lingüística hablamos de glotodiégesis, pues las lenguas están presentes solo en la historia (poliglotismo implícito). Esta clasificación se amplía - en esto reside la diferencia con las otras clasificacionespara justificar el motivo por el que un personaje habla otra lengua distinta a la materna. En este sentido, Stockhammer propone el término de glotopithanón (implícito o explícito), si se puede determinar la motivación verosímil del uso de una lengua extranjera, o de glotoaporía si es imposible determinar la lengua del mundo ficcional. Ejemplifico usando el corpus que nos ocupa.

Cuando en Las etiópicas de Heliodoro, el jefe egipcio de los bandidos (Tíamis) se dirige a los prisioneros griegos, se marca claramente que usa el egipcio como lengua de comunicación: «Tíamis [...] después de ordenar a Cnemón que tradujera sus palabras a los extranjeros (este ya comprendía la lengua egipcia, pero Tíamis aún no dominaba a la perfección el griego), tomó la palabra y dijo: -Camaradas de armas...» (Heliodoro 1979, 96). No se usa ninguna marca en el significante del discurso (junto al original griego, nada aparece escrito en egipcio), por lo que estamos ante una narración glotodiegética en la que se justifica la comprensión de los prisioneros por la interpretación del griego Cnemón, que lleva ya un tiempo en Egipto en búsqueda de Tisbe.

En Eustorgio y Clorilene, el consejero que acompaña al duque de Moscovia decide hablarle en polaco cuando no es esta la lengua materna de ninguno de los dos: «Pigmerio en lengua polaca dijo a Eustorgio: -este, señor, es el padre de aquel mozo que murió y enterramos en la cueva, que en el pecho

6. Una descripción del aparato terminológico de Stockhammer también se puede ver en Babel (2015, 52-58), quien lo aplica para analizar el motivo de la ficcionalización de la traducción en $\mathrm{He}-$ liodoro, Cervantes y Goethe. 
le hallé yo una carta para él» (Suárez 1629, 82r. ${ }^{\circ}$ ). Estamos ante una narración glotodiegética porque el estilo directo va en español, no en polaco. Si el significante literario fuera efectivamente en polaco, tendríamos una narración glotomimética. Siguiendo con este mismo ejemplo, el carácter glotopithanón del texto ficcional es explícitamente verificable, ya que se nos dice del consejero que es «uno y el primero en todas la lenguas, naciones y provincias, gran filósofo, jurista y teólogo» (Suárez 1629, $73 \mathrm{r}^{\circ}$ ).

La mayoría de las marcas en el Persiles son también glotodiegéticas ${ }^{7}$. Véase en el caso de Transila, quien a menudo sirve de intérprete y domina, entre otras, el polaco: «Traían sobre los hombros a una mujer bárbara, pero de mucha hermosura, la cual, antes que otro alguno hablase, dijo en lengua polaca: -A vosotros, quienquiera que seáis [...]. Entendióla muy bien Arnaldo» (Cervantes 2004, 146-147). Difícil es determinar la razón por la que Transila domina el polaco; menos aún su lengua materna, aunque concedamos que procede de Hibernia, topónimo antiguo de Irlanda, que Cervantes también menciona, pero utiliza explícitamente para referirse a islas distintas. La indeterminación de la geografía nórdica corre paralela a la indeterminación lingüística del polaco, que funciona en la ficción a modo de lingua franca o diglosia (Losada 2017, 253) entre los territorios bárbaros del Norte ${ }^{8}$, de ahí que sea entendida también por el príncipe danés, Arnaldo, o Cratilo, rey de Bituania. Podemos considerarlo un caso de glotopithanón implícito, pues sabemos que Transila, huyendo de su patria, transitó por las islas septentrionales donde terminó siendo vendida como esclava.

\section{LENGUAS Y MODELO DE PRÍNCIPE}

Son en su mayor parte glotodiegéticos, por tanto, el modelo griego y el helenizante, porque presentan explícitamente, sin una mención directa en el discurso, qué otras lenguas se hablan, cómo se comunican los personajes o cómo se usan traductores, mientras la lengua del discurso permanece unitaria. Además, a veces, se expresa explícita o implícitamente por qué se hablan o se entienden los personajes: debido al aprendizaje, a la patria de origen, al propio oficio, a estancias en el extranjero, ya sean exilios, cautiverio, etc.

Historia de las fortunas de Semprilis y Genorodano, de Juan Enríquez de Zúñiga, y Eustorgio y Clorilene: historia moscóvica, de Enrique Suárez de Mendoza, forman parte de la estela que continúa la consolidación del género helenizante fijada por Lope de Vega y Miguel de Cervantes. Se trata de obras poco estudiadas que generalmente se clasifican con el membrete de imitación

7. Cuando los falsos cautivos relatan su (falso) cautiverio, intentan hacerlo cré́ble intercalando los insultos turcos que les proferían (Cervantes 2004, 530-531). No se trata de glotomímesis indicativa, pues la lengua de la diégesis no es el turco, sino castellano mezclado con palabras turcas, en un ejemplo de code-switching.

8. Lozano $(1998,103)$ interpreta el polaco como sinónimo de lengua extranjera. 
cervantina: más Semprilis (González Rovira 1996, 293-310; González de Amezúa 1951, 213; Marguet 2004, 65) que Eustorgio (Praag 1939, 238; González Rovira 1996, 311). Aunque ciertamente compartan tópicos o estructuras narrativas, muestran evidentes diferencias, como la ausencia de peregrinación cristiana y menor peso de la temática religiosa, la renuncia a los recursos fantásticos, una distinta caracterización del héroe (Losada 2016) o de la configuración geográfica (Losada 2017). Los trabajos dedicados a Eustorgio y Clorilene la han abordado sobre todo como fuente de inspiración de Calderón para La vida es sueño (Praag 1940; Praag 1963). La declaración de intenciones del prólogo sobre los destinatarios, «a los entendidos moderados entretiene, a los superiores asombra, a los príncipes enseña y a los privados encamina» (Suárez 1629, 6r. ${ }^{\circ}$ ), la sitúan como una novelización de los tratados de educación de príncipes. Los distintos lances y trabajos por los que tiene que pasar Eustorgio -el motivo del viaje no se presentará con propiedad hasta el libro sexto- funcionan a modo de pruebas que van formando su experiencia como futuro monarca guiado de un espíritu cristiano. El aprendizaje va surgiendo en la confrontación con la pléyade de personajes, ya sean coadyuvantes o antagonistas. La presencia continua del consejero Pigmerio -que programáticamente había sido elegido por la madre para la formación- oscurece en buena medida la historia de amor, que queda supeditada a la razón de Estado, por lo que de Clorilene, la protagonista femenina, también se destacarán sus cualidades como futura monarca.

En este contexto queremos analizar el recurso glotoliterario que las obras comparten con Heliodoro y con Cervantes, para mostrar que más allá de la mera imitación se convierten en sus dignos émulos. Las dos novelas presentan un extremo cuidado en marcar la verosimilitud lingüística en el intercambio entre personajes, en particular en sus protagonistas. El héroe masculino de la obra de Suárez de Mendoza, Eustorgio, domina todas las lenguas que van apareciendo como parte de la diégesis, poniéndolas en práctica, así como otras muchas en las que ha sido instruido. Es un caso de glotopithanón explícito: «Instruido, pues, y eminente Eustorgio en letras humanas y divinas, en las lenguas hebrea, griega, latina, arábiga, moscovita, polaca, toscana, francesa, española, tártara y otras de algunos reinos de las Indias» (Suárez 1629, 73v. ${ }^{\circ}$ ).

$\mathrm{Su}$ instrucción como príncipe heredero corre a cargo de su leal consejero, el italiano Pigmerio, quien, también versado en numerosas lenguas, ha estado al servicio de reyes y príncipes en varios países europeos y asiáticos. La formación es completada por la reina madre, Celidora, quien resume sus consejos prudenciales sobre el control de los afectos, el tiempo o los bienes materiales expresándolos en latín: «Reparad en ese papel donde los leeréis mejor apuntados, que yo los he sabido entender: Rex esse vis? Te rege imperator. Affectibus tuis impera. Vis esse dives?...» (Suárez 1629, 73r). Es la única vez en que una lengua se presenta glotomiméticamente en la obra, de ahí que su uso destaque más aún, si tenemos en cuenta que las citas o los discursos eruditos en latín están totalmente ausentes, a diferencia, por ejemplo, del Peregrino de Lope de Vega o de Semprilis. 
El conocimiento de latín es fundamental para el gobernante, pues, como décadas más tarde escribirá Saavedra Fajardo en su manual político, le permite ganar voluntades, aplauso y estimación, tanto en su nación como en el extranjero (Saavedra 1999, 888); recomienda, incluso, un estudio práctico de lenguas extranjeras haciéndose rodear en la corte de «meninos de diversas naciones» (Saavedra 1999, 235), como, por otro lado, ya recogía Francisco de Monzón en Libro primero del espejo del príncipe cristiano como de gran provecho para el príncipe 9 .

El papel que lee la reina Celidora bien puede representar de forma especular un clásico manual de educación de príncipes ${ }^{10}$. González Rovira (1996, 312) ya apuntó los paralelismos y citas textuales tomadas de El privado cristiano (1626) de Enrique de Mendoza, quien escribe el citado prólogo a la novela reseñando su contenido didáctico. El libro de Enrique de Mendoza, por su parte, se ofrece como documentos, avisos y consejos entre los que se encuentran de forma ficcionalizada los que le da el rey polaco Ladislao a su hijo Segismundo ${ }^{11}$.

El uso del latín como lingua franca que facilita la comunicación durante un viaje se encuentra tematizado a menudo en la ficción barroca. Estebanillo González consigue salvarse del ajusticiamiento en Inglaterra, pues puede dirigirse en latín a un caballero al que estuvo «latinizando más de media hora» (Cid 1990, 358), nos dice en tono burlesco, por otro lado, típico del género. La pendencia que le había puesto en esa situación surge precisamente de un contexto lingüístico: por insultar en español a un «inglés españolado» (Cid $1990,355)^{12}$ que pudo entenderlo.

A pesar de que como se apunta en el Peregrino, «es insufrible trabajo caminar al lado del que por lo menos ignora la lengua latina» (Vega 2016, 247), no es el latín lengua de comunicación durante los viajes de Eustorgio. Sí, en cambio, en Semprilis, donde el papel de experto en lenguas, «particularmente la griega y latina» (Enríquez 1629, 48r. ${ }^{\circ}$ ), corre a cargo de Nitophormio, sacerdote de Apolo y anciano consejero de la corte en la Isla Bárbara. Su mediación a través del religioso que acompaña al grupo de viajeros «como más experimentado en latín» (Enríquez $1629,48 \mathrm{r}^{\circ}{ }^{\circ}$ ) posibilitará el entendi-

9. «Debrían de haber personas en casa del príncipe que hablassen en estos diversos lenguajes con ellos: que claro está que ellos no van de andar de tierra en tierra como mercaderes para aprenderlos» Monzón $\left(1544,49 \mathrm{v} .^{\circ}\right)$. Todo el capítulo octavo está dedicado a las «lenguas y sciencias humanas que es bien que sepan los príncipes» $\left(1544,49 \mathrm{r}^{\circ}\right)$.

10. Estos mismos consejos - con una ligera variante, pues se elimina la referencia al obispo-son atribuidos a Felipe II en Elogio a Felipe II (1604) de Cristóbal Pérez de Herrera, autor también de un libro de Proverbios Morales (1618) dedicado al joven Felipe IV.

11. No se debe a la casualidad que Polonia esté también presente en Semprilis y que compartan temas y espacios geográficos. Enríquez de Zúñiga prologó a su vez El privado cristiano de Enrique de Mendoza, con lo que es probable que los tres autores mantuvieran una relación estrecha. Debido a la falta de datos biográficos, González Rovira $(1996,312)$ sugiere incluso que Enrique de Mendoza y Enrique Suárez de Mendoza podrían ser la misma persona.

12. A Estebanillo ya se le había avisado de que «callase porque había muchos en aquel reino que sabían hablar español» (Cid 1990, 355). Covarrubias recoge -sub voce España- el sentido del término: «Españolado, el extranjero que ha deprendido la lengua y traje de España» $(2006,831)$. 
miento en la isla. El latín funciona, por otro lado, glotomiméticamente en varios episodios donde los personajes se sirven de citas latinas. Se ve con claridad en la discusión que un clérigo y un capitán tienen en plaza pública sobre la recurrente disputa entre las armas y las letras (Enríquez 1629, 96v. ${ }^{\circ}$ $97 \mathrm{v} .^{\circ}$ ), en la que las referencias explícitas en latín a Ovidio, Apuleyo o Plutarco son parte del diálogo (y no un excurso erudito del narrador).

El uso programático de las lenguas en la narración para destacar la importancia de su conocimiento en los futuros reyes distingue, sin embargo, a las dos novelas y las diferencia en la manera que se ofrecen como una novelización de los espejos de príncipes. Sus centros temáticos giran en torno a las dificultades de acceso al poder real, como igualmente ocurre en Las etiópicas o en el Persiles. Tras numerosos trabajos, Genorodano y Semprilis terminarán accediendo al trono de Aragón; Eustorgio y Clorilene, al trono de Moscovia, pero el énfasis que se pone en el recurso lingüístico como seña de identidad de los príncipes no es comparable. Genoradano habla tres lenguas en total, el castellano, el tártaro y la lengua bárbara, que aprende debido a los diferentes encuentros provocados por los naufragios y cautiverios que sufre desde que abandona Aragón recién nacido. El castellano, que identificamos como su lengua materna, deducimos que lo aprende del aya y del anciano (Ricaredo) que lo acompañan en sus primeros años de vida. La única referencia a la educación humanística en el entorno cortesano se da, por contraste, en la corte de la Isla Bárbara. Laureano, príncipe heredero, que accederá al trono con Sitebusa, ha sido criado en secreto por Nitophormio para alejarlo del tirano usurpador que gobierna la Isla. Laureano aprende del anciano sacerdote su lengua materna, el griego y el latín, además de formarse en su propia tradición escrita. Enríquez de Zúñiga traza un paralelismo entre Genorodano y Laureano al presentarlos como un hombre natural que, empujado a un aislamiento forzoso, es capaz de deducir su ser de la observación de la naturaleza sin más ayuda que su intelecto (recuérdese cómo Gracián lo retoma en la figura de Andrenio en el Criticón), pero no cree necesario reforzar el aspecto lingüístico en Genorodano, quizá para mantener el suspense de la diferencia social que puede dificultar su matrimonio con Semprilis, quien, por cierto, no hablará ninguna otra lengua excepto la materna, el castellano.

Distinto es, como estamos viendo, el uso en la caracterización de los príncipes herederos que lleva a cabo Suárez de Mendoza. No solo se limita al protagonista masculino; Eustorgio usará efectivamente como mínimo seis lenguas: lengua moscovita, polaco, lengua indígena, latín, francés y castellano. La protagonista femenina, Clorilene, además de la materna, se servirá de otras dos, que aprende en la corte gracias a la transferencia cultural presente en Moscovia: el castellano gracias a Leoncio, hijo de un español exiliado; la lengua indígena gracias al indio esclavizado por corsarios ingleses. No falta, por tanto, el glotopithanón explícito cuando más adelante, prefigurando su capacidad de reina, se dirija, durante la misma escena, a interlocutores distintos en cada una de sus lenguas: español a los sacerdotes cautivos, lengua de Moscovia al rey de los bárbaros (el indio esclavo) y lengua indígena al pueblo. 
Suárez de Mendoza es especialmente cuidadoso cada vez que cambia de parlamento -glotodiegéticamente se marca siempre un inquit- en hacer notar quién habla qué lengua:

Y volviéndose a Eustorgio le dijo: -«calla y espera». Y levantándose de su silla en voz alta en lengua de Castilla, con que admirados todos creyeron ser más divina que humana, pues sabía las lenguas en que no había nacido, puso los ojos en los religiosos y esforçándolos, dijo: -«Buena noticia, padres venerables...».

y volviendo al rey en la lengua de Mosca (en que antes con él había hablado) le dijo: - «cristiano eres, ayuda mi intención y no se te representen inconvenientes...».

Y volviendo al pueblo para poner por obra su designio en lengua de la isla, dijo: - «no hay cosa con que más se agraden los dioses que con los verdaderos sacrificios» $\left(\right.$ Suárez $\left.1629,93 \mathrm{r} .{ }^{\circ} / \mathrm{v}^{\circ}\right)$.

Se trata de un magnífico ejemplo del uso de las lenguas como herramienta de gobierno, que prefigura las competencias para reinar de Clorilene. La relación directa con los súbditos sin necesidad de intérpretes o traducciones ya era típica en los tratados renacentistas ${ }^{13}$. Durante el Barroco se añade la utilidad del conocimiento de lenguas como prevención frente al engaño al que siempre está expuesto el príncipe. Será una máxima de prudencia recomendada en las Empresas políticas:

El conocimiento de diversas lenguas es muy necesario en el príncipe, porque el oír por intérprete, o leer traducciones está sujeto a engaños, o a que la verdad pierda su fuerza y energía, y es gran desconsuelo del vasallo que no le entienda quien ha de consolar su necesidad, deshacer sus agravios y premiar sus servicios (Saavedra 1999, 231).

La función de engaño por medio de la traducción o de la lengua en narraciones glotoliterarias la pusieron de manifiesto Brioso y Brioso $(2002,82)$. En el Amadís de Gaula, aunque la presencia de lenguas no es un hecho relevante, aparecen alusiones, por ejemplo, a cómo Amadís finge no entender para aprovecharse de la ocasión ${ }^{14}$ o cómo la doncella Grinfesa es obligada a expresarse en francés para que únicamente Lisuarte comprenda el mensaje ${ }^{15}$.

13. «Paresce grande magestad saber entender y hablar con los embaxadores que de diversas partes vienen a negociar con él, sin lengua ni intérprete. Como haçia aquel grande rey Mithridates»» (Monzón 1544, 49v. ${ }^{\circ}$ ).

14. «Él dava a conocer que lo no entendía. Y Esplandían començó a llamar a altas bozes al conde Argamón que se llegasse allí, que el Cavallero Griego no le entendía su lenguaje.» (Rodríguez 1987, 1259).

15. «Y diéronle un escrito en latín que de ante tenían fecho para que lo diese al rey Lisuarte y a la reina Brisena; y mandáronla que no fablasse ni respondiesse sino por el lenguaje francés en tanto que entre ellos estuviesse» (Rodríguez 1987, 1240). 
Cervantes no llega a usarlo en propiedad en Persiles; únicamente se sirve de la treta del mudo en el personaje de Rutilio: «Para disimular la lengua, y que por ella no fuese conocido por estranjero, me fingí mudo y sordo» (Cervantes 2004, 193). Sí la encontramos en Heliodoro, por ejemplo, cuando Nausicles consigue engañar a Clariclea, confiada porque se dirige a ella en una lengua que conoce: «En voz baja y en griego, para evitar que los presentes lo comprendieran» (Heliodoro 1979, 242). Lope de Vega tematiza la función del engaño lingüístico desde una perspectiva cómica (Canonica 1996, 115) en el auto sacramental intercalado en el Peregrino, poniéndola en boca del personaje del Juego «perche si il inganno tiene / moltas faccias, li conviene / no usar di una lingua sola» (Vega 2016, 546). Dentro de la trama se sirve directamente del recurso con cierta ironía cuando Nise disfrazada de hombre y hablando en árabe -aprendido por su cautiverio-, en lo que podíamos llamar un doble engaño, miente sobre su identidad al dirigirse a un Pánfilo confuso (Vega 2016, 504-506).

Un dominio nativo de una lengua aprendida es asimismo un buen recurso narrativo aplicable a la ocultación que debe practicar el gobernante. Hemos visto como se destaca en Clorilene esta capacidad casi divina e igualmente se dirá de Eustorgio, que le permite con facilidad hacerse pasar por embajador en Francia o directamente fingirse español: «Eustorgio respondió que era español y venía de la corte. Y púdolo decir porque hablaba todas las lenguas, como si hubiera nacido y se hubiera criado en el natural de cada una dellas» (Suárez 1629, 119 r. $^{\circ}$ ). Suárez de Mendoza busca caracterizar las competencias excepcionales de los futuros gobernantes, pero no se limita solo a ellos. El recurso está perfectamente imbricado en la obra en todos los personajes y mantiene una gran coherencia. Cuando Pigmerio se dirige a Eustorgio en polaco sobre el mancebo muerto teniendo delante al español Rafael, usa la cautela, pues este entiende también la lengua de Moscovia por su exilio en Esmolensco (Smolénsk). Una cautela compasiva, podríamos decir, que define la rectitud de Pigmerio, pues Rafael es el padre del joven.

Según el tópico, son modélicas en el dominio de lenguas precisamente las naciones septentrionales, quienes -escribe Saavedra Fajardo- salen a recorrer el mundo en busca de noticias, pues la «peregrinación es gran maestra de la prudencia cuando se emprende para informar» (Saavedra 1999, 752). Un peregrinar que conlleva formación y que, recordemos, en nuestras dos novelas no tiene carácter religioso a diferencia del Persiles o del Peregrino, sino que se limita al sentido de andar por tierras lejos de la patria (Covarrubias 2006, 1356). En Eustorgio, el viaje del rey de Suecia (Nomberto) a Moscovia se justifica, aparte de por motivos matrimoniales -poder conocer a su futura esposa- por una cuestión de conocimiento político que ayudará a mejorar el reino: «Ver ajenos Estados y concebir bríos para conservar y aumentar los proprios [...], para experimentar gobiernos diferentes, e imitando lo loable de los unos, establecerlo en mis reinos, extirpando lo injusto dellos» (Suárez 1629, 72r. ${ }^{\circ}$ ).

La gran capacidad lingüística de los pueblos del norte, su pericia y memoria para las lenguas, ya la recogía Huarte de San Juan, aunque envuelta en 
crítica a los teólogos de la Reforma ${ }^{16}$. El tópico se torna positivo en estas novelas, cierto es que sin dejar de reseñar que Eustorgio y Clorilene son príncipes cristianos en países septentrionales. En Semprilis forma parte de la presentación positiva del imagotipo polaco, muy diferente, por cierto, de la imagen negativa que normalmente se asocia en la literatura del Siglo de Oro con la magia, la intriga palaciega, la violencia, la venganza o el carácter colérico (Losada 2017, 255-256). El polaco Kasimiro, rey de la católica Polonia, cuenta con peso específico en la trama y en el desenlace. Enamorado de Semprilis, la acompañará hasta el final constituyendo una pieza clave en las anagnórisis finales. Podríamos equiparar hasta cierto punto el papel de Kasimiro con el del príncipe danés Arnaldo del Persiles, aunque sus diferencias son evidentes. Kasimiro no muestra la ambivalencia sospechosa de Arnaldo, es discreto, humanista y no solo sabe controlar sus pasiones, sino que ofrece a sus compañeros de viaje consejos prudenciales. En lo referente a la cuestión lingüística, de nuevo, podemos constatar ejemplos de glotodiégesis con inquit. Cuando Semprilis llega a Polonia -recordemos que solo domina el español- la comprensión se hace posible no solo por los conocimientos de español de Kasimiro «por ser el rey muy experto en lenguas» (Enríquez 1629, 33v. ${ }^{\circ}$ ), sino de todo su pueblo, "por ser naturalmente los polacos inclinados a saber muchas lenguas» (Enríquez 1629, 31r. ${ }^{\circ}$ ).

La capacidad de los polacos para las lenguas que refiere Enríquez de Zúñiga bien podría formar parte del sustrato del imagotipo presente en toda Europa. La encontraremos más tarde en la Völkertafel austriaca (Mörke 2001, 82-84), una de las primeras representaciones de los estereotipos nacionales, que otorga a los polacos ${ }^{17}$ superioridad científica en las lenguas (Waissenberger 1983, 265). Por otro lado, el glotopithanón implícito no solo se debe a su condición de monarca de un país septentrional. Gracias a una analepsis sabremos que ya había pasado por el reino de Aragón cuando era príncipe en su deseo de conocer España, viaje clave que condicionará las anagnórisis finales de la novela y que justifica verosímilmente el conocimiento del español.

\section{CONCLUSIÓN}

La taxonomía que hemos propuesto siguiendo a Stockhammer se ha limitado a una clasificación de las manifestaciones del multilingüismo en su nivel discursivo. Su definición, más apegada a la tradición teórica narratológica,

16. «La vanilocuencia y parlería de los teólogos alemanes, ingleses, flamencos, franceses y los demás que habitan el Septentrión echó a perder el auditorio cristiano con tanta pericia de lenguas, con tanto ornamento y gracia en el predicar» (Huarte 1989, 451).

17. Puede que no sea más que una alegre coincidencia que la familia de los Gracianes, la descendencia española del embajador polaco en España, Jan Dantyszek (Juan Dantisco), terminara a cargo de la Secretaría de Lenguas. 
creemos que facilita una aplicación metodológica más amplia al añadir el carácter verosímil del conocimiento de las lenguas por los personajes.

Podría resultar obvio que, tratándose de novelas donde abundan los encuentros transculturales, la integración de las lenguas debería reproducirse de forma generalizada y coherente. No es el caso en la ficción de la Edad Moderna ni tampoco a menudo -si se me permite, salvando las distancias- en la ficción cinematográfica, donde la dificultad lingüística se resuelve, en el mejor de los casos, con un acento macarrónico (glotomímesis indicativa) sin rastro de motivación verosímil (glotophitanón) ${ }^{18}$.

La sola mención aislada no implica tampoco una coherencia interna a lo largo del texto, difícil de mantener, sobre todo en obras con un alto componente dialógico. Como ya apuntaban Brioso y Brioso $(2002,85)$, para Cervantes, el pacto ficcional convirtió quizás en convención la omisión de las marcas glotoliterarias. De ahí que construir el relato para hacer verosímil de manera más o menos sistemática la comunicación de personajes de distinta procedencia sea una gran novedad en Heliodoro, que Cervantes incorpora en el Persiles, donde recoge la mención a más de una docena de lenguas (Armas Wilson 2000, 104). Con todo, se trata de un verdadero reto a la mímesis representar en un medio monolingüe un discurso plurilingüe (Stenberg 1981, 222). Los personajes que paulatinamente van entrando en escena, Cloelia, Transilia, Rutilio, Antonio, etc., son presentados a menudo con un inquit que sirve de caracterización -Manuel de Sosa Coitiño habla y canta «en medio castellano y medio portugués» (Cervantes 2004, 197)-, o de puente para entablar el primer contacto, como cuando los viajeros se acercan a la marina de Golandia y el diálogo oscila de forma rápida entre español, inglés y lenguas desconocidas, «en lengua que el[1a] entendió» $(2004,207)$. Sin embargo, a medida que se conforma el grupo de viajeros y se entablan las conversaciones, no podemos deducir cómo se continúa, qué habla o entiende cada uno, rayándose a veces la glotoaporía. Cervantes caracteriza intradiegéticamente a la perfección los problemas de comunicación, la necesidad de traductor, el encuentro transcultural, pero, como explican Brioso y Brioso $(2002,86)$ «por cansancio del empleo del motivo, o, sobre todo, porque éste introduciría una grave complicación en el relato», no siempre mantiene las marcas glotoliterarias con coherencia ni logra incorporarlas a todo el entramado de la novela. De Auristela no podemos decir con propiedad qué lenguas domina, parece que el castellano, aunque a veces se explicita su dificultad para comprenderlo (Cervantes 2004, 425), como le ocurre a Periandro, quien «no muy despiertamente sabía hablar la lengua castellana» (Cervantes 2004, 70), pero que, en cualquier caso, está mucho más capacitado que Auristela, pues además del

18. La presencia de lenguas extranjeras está presente desde los inicios del cine sonoro (por razones estéticas o políticas), pero tradicionalmente se ha tendido a minimizar su presencia. Subtitular parcialmente diálogos cinematográficos (variantes, lenguas inventadas, etc.) es un hecho reciente O’Sullivan $(2007,82)$. 
noruego (su lengua materna) entiende o habla alemán (tudesco), polaco, español y latín (Davenport 2016, 217).

Debemos decir que no falta la justificación verosímil del aprendizaje (glotophitanón explícito), aunque sea débilmente. Cervantes también recurre al tópico de las capacidades de los pueblos del norte: «Y, como es uso de los setentrionales ser toda la gente principal versada en la lengua latina y en los antiguos, éralo asimismo Periandro» (2004, 503-504) y a la mención del monasterio de Santo Tomás en Groenlanda, «en el cual hay religiosos de cuatro naciones: españoles, franceses, toscanos y latinos; enseñan sus lenguas a la gente principal de la isla, para que, en saliendo della, sean entendidos por do quiera que fueren» $(2004,706-707)$, pero, como opina Pelorson $(2003,45)$, el recurso llega demasiado tarde al final de la novela.

Resulta evidente que las obras de Enríquez de Zúñiga y Suárez de Mendoza recogen el tópico y lo desarrollan en tal amplitud que podemos considerarlo una marca del género helenizante. Desde luego, se podrán encontrar momentos en los que se pierda la coherencia interna, pero en general sería equivocado tildarlas de simples imitaciones cervantinas cuando, en esta técnica, son émulos muy dignos de sus modelos. Especialmente en Eustorgio y Clorilene, donde el recurso se pone con precisión verosímil al servicio de la caracterización de monarcas y validos, como parte de la novelización de manuales de educación de príncipes.

\section{BIBLIOGRAFÍA CITADA}

Armas Wilson, Diana. 2000. Cervantes, the Novel, and the New World. Oxford: University Press.

Armstrong-Roche, Michael. 2009. Cervantes' epic novel: empire, religion, and the dream life of heroes in Persiles. Toronto: University of Toronto Press.

Babel, Reinhard. 2015. Translationsfiktionen: Zur Hermeneutik, Poetik und Ethik des Übersetzens. Bielefeld: transcript Verlag.

Bajtín, Mijail. 1989. Teoría y estética de la novela. Madrid: Taurus.

Berlaimont, Noël de. 1608. Dictionario. Coloquios o dialogos en cuatro lenguas, Flamenco, Frances, Español y Italiano. Anvers: Hieronymus Verdussen.

Blanco, Mercedes. 2016. «El renacimiento de Heliodoro en Cervantes». eHumanista/Cervantes 5: 103-138.

Brioso Sánchez, Máximo y Héctor Brioso Santos. 2002. «Sobre la problemática relación entre Heliodoro y el "Persiles y Sigismunda" de Cervantes: el motivo de la comunicación lingüística». Criticón 86: 73-96.

Brugnolo, Furio y Vizenzo Orioles, eds. 2002. Eteroglossia e plurilinguismo letterario. II. Plurilinguismo e letteratura. Roma: Il Calamo.

Cáceres Würsig, Ingrid. 2004. «Breve historia de la secretaría de interpretación de lenguas». Meta: Journal des traducteurs 49 (3): 609-628.

Canavaggio, Jean. 2014. Retornos a Cervantes. Nueva York: IDEA/IGAS.

Canonica de Rochemonteix, Elvezio. 1991. El poliglotismo en el teatro de Lope de Vega. Kassel: Edition Reichenberger. 
Canonica de Rochemonteix, Elvezio. 1994. «La conciencia de la comunicación interlingüística en las obras dramáticas y narrativas de Cervantes». En Cervantes: estudios en la víspera de su centenario, ed. José Ángel Ascunce Arrieta, 19-42. Kassel: Edition Reichenberger.

Canonica de Rochemonteix, Elvezio. 1996. «Lenguas en la escena: el plurilingüismo en el teatro prelopesco». En Studia Aurea. Actas del III Congreso de la Asociación Internacional Siglo de Oro 2, eds. Ignacio Arellano, Carmen Pinillos, Frédéric Serralta y Marc Vitse, 109-117. Pamplona: GRISO.

Canonica de Rochemonteix, Elvezio. 2002. «Aspetti del plurilinguismo nelle letterature iberiche, dalle origini al secolo d'oro». En Eteroglossia e plurilinguismo letterario. II. Plurilinguismo e letteratura, eds. Furio Brugnolo y Vizenzo Orioles, 179-194. Roma: Il Calamo.

Cervantes Saavedra, Miguel de. 2004. Los trabajos de Persiles y Sigismunda, ed. Carlos Romero Muñoz. Madrid: Cátedra.

Cid, Jesús Antonio, ed. 1990. La vida y hechos de Estebanillo González, hombre de buen humor compuesto por el mesmo. Madrid: Cátedra.

Covarrubias Horozco, Sebastián de. 2006. Tesoro de la lengua castellana o española, eds. Ignacio Arellano y Rafael Zafra. Madrid: Iberoamericana-Frankfurt am Main: Vervuert.

Davenport, Randi L. 2016. «El Norte, la oralidad y la verosimilitud lingüística del héroe en el Persiles». En Recreaciones quijotescas y cervantinas en las artes. Cervantes y su obra, ed. Carlos Mata Induráin, 211-221. Pamplona: EUNSA.

Egido, Aurora. 2007. «Cervantes frente a Babel (Don Quijote I)». En Retos del Hispanismo en la Europa Central y del Este: actas del Congreso Internacional, Cracovia 14-15 de octubre de 2005, 25-41. Madrid: Palafox-Pezuela.

Enríquez de Zúñiga, Juan. 1629. Historia de las fortunas de Semprilis y Genorodano. Madrid: Juan Delgado.

Forster, Leonard Wilson. 1970. The Poets Tongues: Multilingualism in Literature. Cambridge: University Press.

González de Amezúa y Mayo, Agustín. 1951. «Un escritor olvidado. El Dr. D. Juan Enríquez de Zúñiga». En Opúsculos histórico-literarios, ed. Agustín González de Amezúa y Mayo, 280-306. Madrid: Consejo Superior de Investigaciones Científicas.

González Rovira, Javier. 1996. La novela bizantina de la edad de oro. Madrid: Gredos.

Gracián, Baltasar. 1997. El discreto, ed. Aurora Egido. Madrid: Alianza Editorial.

Grutman, Rainier. 2002. «Les motivations de l'hétérolinguisme: réalisme, composition, esthétique». En Eteroglossia e plurilinguismo letterario. II. Plurilinguismo e letteratura, eds. Furio Brugnolo y Vizenzo Orioles, 329-349. Roma: Il Calamo.

Heliodoro. 1979. Las etiópicas o Teágenes y Cariclea. Madrid: Gredos.

Helmich, Werner. 2016. Ästhetik der Mehrsprachigkeit. Zum Sprachwechsel in der neueren romanischen und deutschen Literatur. Heidelberg: Universitätsverlag Winter.

Huarte de San Juan, Juan. 1989. Examen de ingenios para las ciencias, ed. Guillermo Serés. Madrid: Cátedra.

Losada Palenzuela, José Luis. 2016. «El toro y el héroe: variación del motivo en la narrativa de Juan Enríquez de Zúñiga». Edad de Oro 35: 239-250. https://doi.org/10.15366/ edadoro2016.35.014.

Losada Palenzuela, José Luis. 2017. «Desplazamiento de la imagen septentrional: Polonia en La historia de las fortunas de Semprilis y Genorodano». En Ficciones entre mundos. Nuevas lecturas de «Los Trabajos de Persiles y Sigismunda» de Miguel de Cervantes, eds. Hanno Ehrlicher y Jörg Dünne, 253-273. Kassel: Reichenberger.

Lozano Renieblas, Isabel. 1998. Cervantes y el mundo del Persiles. Alcalá de Henares: Centro de Estudios Cervantinos. 
Marguet, Christine. 2004. Le roman d'aventures et d'amour en Espagne XVIème - XVIIème siècles: L'utile et l'agréable. París: Editions L'Harmattan.

Martinell Gifre, Emma, Mar Cruz Piñol y Rosa Ribas, eds. 2000. Corpus de testimonios de convivencia lingüistica (ss. XII-XVIII). Kassel: Edition Reichenberger.

Martínez Tortajada, Sònia y Emma Martinell Gifre. 2017. Contacto de lenguas y pueblos: el español y el alemán en la Austria de los siglos XVI y XVII. Kassel: Edition Reichenberger.

Monzón, Francisco de. 1544. Libro primero del espejo del príncipe christiano. Lisboa: Luis Rodríguez.

Mörke, Olaf. 2001. «Die Europäisierung des Nordens in der Frühen Neuzeit. Zur Wirkmächtigkeit von Vorstellungswelten in der Landschaft Europas». En Ultima Thule: Bilder des Nordens von der Antike bis zur Gegenwart, Imaginatio borealis, Bd. 1, ed. Annelore Engel-Braunschmidt, 67-91. Frankfurt am Main: Peter Lang.

O'Sullivan, Carol. 2007. «Multilingualism at the Multiplex: A New Audience for Screen Translation?». Linguistica Antverpiensia, New Series. Themes in Translation Studies 6: 81-95.

Pelorson, Jean-Marc. 2003. El desafio del Persiles. Seguido de un estudio onomástico por Dominique Reyre. Toulouse: Presses Universitaires du Mirail.

Praag, Jonas Andries van. 1939. «Eustorgio y Clorilene, Historia Moscovica, de Enrique Suárez de Mendoza y Figueroa». Bulletin Hispanique 41 (3): 236-265.

Praag, Jonas Andries van. 1940. «Una fuente de la vida es sueño de Calderón». Neophilologus 25 (1): 250-251.

Praag, Jonas Andries van. 1963. «Otra vez la fuente de La vida es sueño». Studia Philologica. Homenaje ofrecido a Dámaso Alonso 3: 551-562.

Radaelli, Giulia. 2014. «Literarische Mehrsprachigkeit: ein Beschreibungsmodell (und seine Grenzen) am Beispiel von Peter Waterhouses Das Klangtal». En Philologie und Mehrsprachigkeit, eds. Till Dembeck y Georg Mein, 157-182. Heidelberg: Winter.

Rodríguez de Montalvo, Garci. 1987. Amadis de Gaula, ed. Juan Manuel Cacho Blecua. Madrid: Cátedra.

Saavedra Fajardo, Diego de. 1999. Empresas políticas, ed. Sagrario López Poza. Madrid: Cátedra.

Sánchez, Juan A. 2019. «La lengua perfecta del Persiles». Hipogrifo. Revista de literatura y cultura del Siglo de Oro 7 (1): 263-276.

Sánchez Pérez, Aquilino. 1992. Historia de la enseñanza del español como lengua extranjera. Madrid: Sociedad General Española de Librería.

Sternberg, Meir. 1981. «Polylingualism as Reality and Translation as Mimesis». Poetics Today 2 (4): 221-239.

Stockhammer, Robert. 2015. «Wie deutsch ist es? Glottamimetische, -diegetische, -pithanone, und -aporetische Verfahren in der Literatur». Arcadia 50 (1): 146-172.

Suárez de Mendoza y Figueroa, Enrique. 1629. Eustorgio y Clorilene. Historia Moscóvica. Madrid: Juan González.

Todorov, Tzvetan. 1981. Mikhaïl Bakhtine. Le principe dialogique. Suivi de: Ecrits du Cercle de Bakhtine. París: Le Seuil.

Torres, José B. 2009. «¿Novela bizantina o novela helenizante? A propósito de un término consagrado». En Ars bene docendi. Homenaje al profesor Kurt Spang, eds. Ignacio Arellano, Víctor García Ruiz y Carmen Saralegui, 567-574. Pamplona: Eunsa.

Vega Carpio, Lope de. 2016. El peregrino en su patria, ed. Julián González Barrera. Madrid: Cátedra. 
Waissenberger, Robert, ed. 1983. Die Türken vor Wien: Europa und die Entscheidung an der Donau 1683, 2. ${ }^{\mathrm{a}}$ ed. Viena: Eigenverlag [Katalog zur Sonderausstellung des Historischen Museums der Stadt Wien, 82].

Winford, Donald. 2003. An Introduction to Contact Linguistics. Malden (Massachusetts): Blackwell Publ.

Recibido: 13 de febrero de 2019

Aceptado: 17 de febrero de 2020 